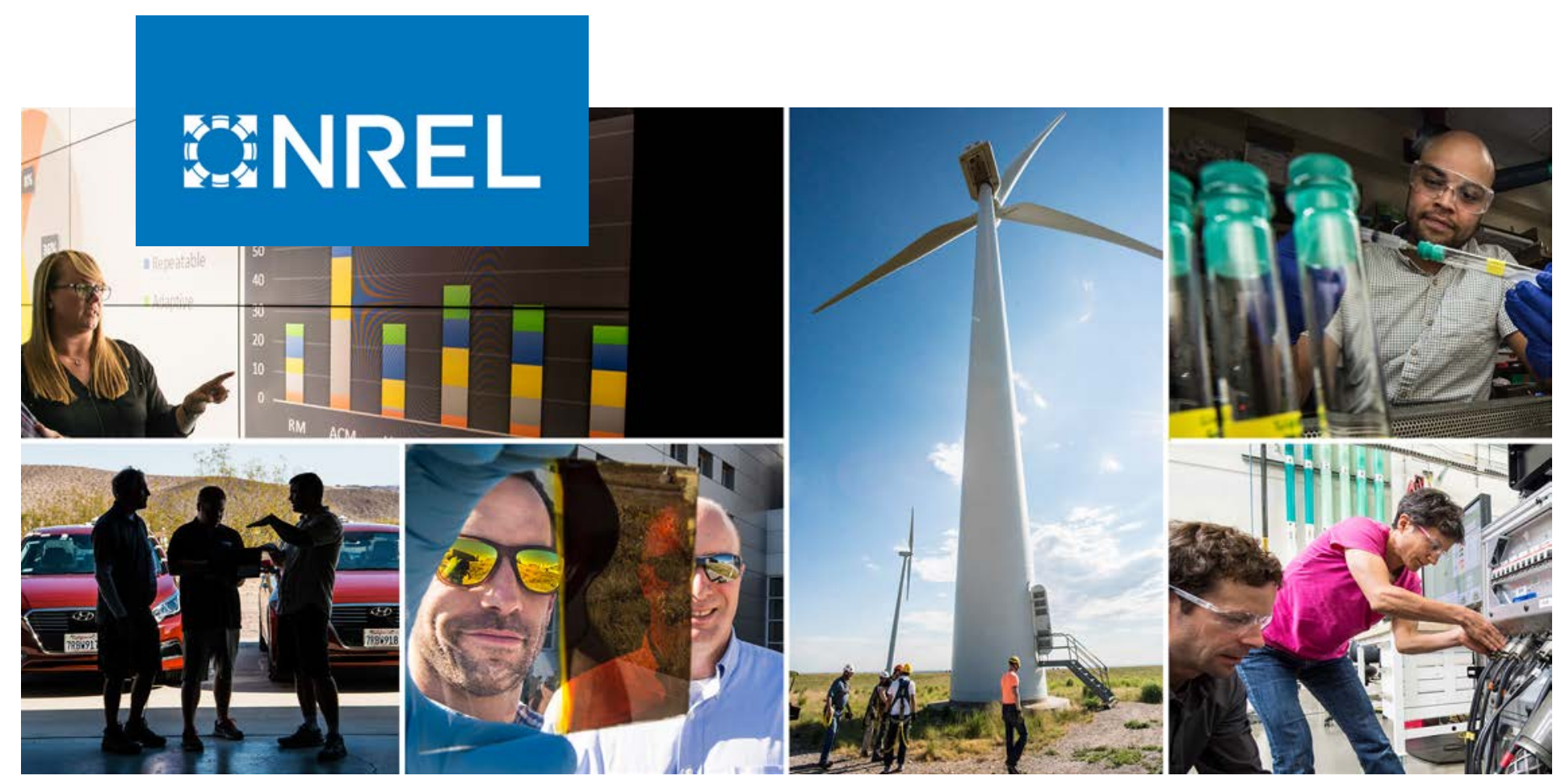

\title{
Development and Validation of a SiC Based 50 kW Grid-Connected PV Inverter
}

\section{Preprint}

Akanksha Singh, ${ }^{1}$ Madhu Chinthavali, ${ }^{2}$ Scott Sudhoff, ${ }^{3}$ Kevin Bennion, ${ }^{1}$ Kumaraguru Prabakar, ${ }^{1}$ Xuhui Feng, ${ }^{1}$ Zhiqiang Wang, ${ }^{2}$ and Steven Campbell ${ }^{2}$

\footnotetext{
${ }^{1}$ National Renewable Energy Laboratory

2 Oak Ridge National Laboratory

${ }^{3}$ Purdue University
}

Presented at the 2018 IEEE Energy Conversion Congress and Exposition Portland, Oregon

September 23-27, 2018

\begin{abstract}
(c) 2018 IEEE. Personal use of this material is permitted. Permission from IEEE must be obtained for all other uses, in any current or future media, including reprinting/republishing this material for advertising or promotional purposes, creating new collective works, for resale or redistribution to servers or lists, or reuse of any copyrighted component of this work in other works.
\end{abstract}

NREL is a national laboratory of the U.S. Department of Energy

Office of Energy Efficiency \& Renewable Energy

Operated by the Alliance for Sustainable Energy, LLC

This report is available at no cost from the National Renewable Energy Laboratory (NREL) at www.nrel.gov/publications.

\section{Conference Paper}

NREL/CP-5D00-70872

October 2018 


\title{
FNREL
}

\section{Development and Validation of a SiC Based 50 kW Grid-Connected PV} Inverter

\section{Preprint}

\begin{abstract}
Akanksha Singh, ${ }^{1}$ Madhu Chinthavali, ${ }^{2}$ Scott Sudhoff, ${ }^{3}$ Kevin Bennion, ${ }^{1}$ Kumaraguru Prabakar, ${ }^{1}$ Xuhui Feng, ${ }^{1}$ Zhiqiang Wang, ${ }^{2}$ and Steven Campbell ${ }^{2}$
\end{abstract}

\author{
${ }^{1}$ National Renewable Energy Laboratory \\ 2 Oak Ridge National Laboratory \\ ${ }^{3}$ Purdue University
}

\section{Suggested Citation}

Singh, Akanksha, Madhu Sudhan Chinthavali, Scott Sudhoff, Kevin Bennion, Kumaraguru Prabakar, Xuhui Feng, Zhiqiang Wang, and Steven Campbell. 2018. "SiC-Based 50-kW Grid-Connected PV Inverter: Preprint." Golden, CO: National Renewable Energy Laboratory. NREL/CP-5D00-70872. https://www.nrel.gov/docs/fy19osti/70872.pdf.

NREL is a national laboratory of the U.S. Department of Energy Office of Energy Efficiency \& Renewable Energy Operated by the Alliance for Sustainable Energy, LLC

This report is available at no cost from the National Renewable Energy Laboratory (NREL) at www.nrel.gov/publications.

Contract No. DE-AC36-08GO28308
Conference Paper NREL/CP-5D00-70872 October 2018

National Renewable Energy Laboratory 15013 Denver West Parkway Golden, CO 80401

303-275-3000 • www.nrel.gov 


\section{NOTICE}

This work was authored in part by the National Renewable Energy Laboratory, operated by Alliance for Sustainable Energy, LLC, for the U.S. Department of Energy (DOE) under Contract No. DE-AC36-08GO28308. Funding provided by the U.S. Department of Energy Office of Energy Efficiency and Renewable Energy Solar Energy Technologies Office. The views expressed herein do not necessarily represent the views of the DOE or the U.S. Government. The U.S. Government retains and the publisher, by accepting the article for publication, acknowledges that the U.S. Government retains a nonexclusive, paid-up, irrevocable, worldwide license to publish or reproduce the published form of this work, or allow others to do so, for U.S. Government purposes.

This report is available at no cost from the National Renewable Energy Laboratory (NREL) at www.nrel.gov/publications.

U.S. Department of Energy (DOE) reports produced after 1991 and a growing number of pre-1991 documents are available free via www.OSTI.gov.

Cover Photos by Dennis Schroeder: (clockwise, left to right) NREL 51934, NREL 45897, NREL 42160, NREL 45891, NREL 48097, NREL 46526 .

NREL prints on paper that contains recycled content. 


\title{
Development and Validation of a SiC Based $50 \mathrm{~kW}$ Grid-Connected PV Inverter
}

\author{
Akanksha Singh ${ }^{1}$,Madhu Chinthavali ${ }^{2}$, Scott Sudhoff ${ }^{3}$, Kevin Bennion ${ }^{1}$, Kumaraguru Prabakar ${ }^{1}$, Xuhui Feng $^{l}$, \\ Zhiqiang Wang $^{2}$, Steven Campbell ${ }^{2}$ \\ ${ }^{1}$ National Renewable Energy Laboratory, Golden, Colorado, 80401, USA \\ ${ }^{2}$ Oak Ridge National Laboratory, Knoxville, Tennessee, 37932, USA \\ ${ }^{3}$ Purdue University, West Lafayette, Indiana, 47907, USA
}

\begin{abstract}
The future power grid will involve increasing numbers of power converters while growing the complexity of the power systems. The future of the power converters is driven by developments in the wide-bandgap semiconductor devices. In this paper, a 50-kW string photovoltaic (PV) inverter designed and developed using all silicon carbide $(\mathrm{SiC})$ semiconductor devices is presented. The inverter design includes an additively manufactured power block, symmetrical Y-core inductors for the ac-side filter, and advanced inverter controls for grid support functionality. This inverter uses the conventional three-phase voltage source inverter topology and optimizes the design for $\mathrm{SiC}$ based devices. The paper includes details on power module design, heatsink optimization, symmetrical Y-core filter inductor design, inverter thermal design, and further experimental validation of the inverter performance. In addition to presenting the quantification of inverter efficiency and quality of the output, the paper presents the validation of advanced grid-support functions required by the IEEE 1547 standards for the interconnection of distributed energy resources.
\end{abstract}

Keywords-advanced grid-support functions, inverter validation, $P V$ inverter, SiC inverter

\section{INTRODUCTION}

The successful integration of hundreds of gigawatts of solar photovoltaics (PV) into the electric power system requires transformative power conversion system designs that optimize various trade-offs in conflicting objectives such as performance, reliability, functionality, and cost. The future of power converters (including PV) will be driven by advancements in wide-bandgap semiconductor devices [1]. These devices can provide very high switching speeds, reduced switching losses, and can reduce the size of the associated filter [2]. In the current market these devices are more expensive than silicon ( $\mathrm{Si}$ ) devices with similar ratings, but recent studies have shown that the economic parameter (cost/power) for wide-bandgap devices

This work was authored in part by Alliance for Sustainable Energy, LLC, the manager and operator of the National Renewable Energy Laboratory for the U.S. Department of Energy (DOE) under Contract No. DE-AC36-08GO28308. Funding provided by U.S. Department of Energy Office of Energy Efficiency and Renewable Energy Solar Energy Technologies Office. The views expressed in the article do not necessarily represent the views of the DOE or the U.S. Government. The U.S. Government retains and the publisher, by accepting the article for publication, acknowledges that the U.S. Government retains a nonexclusive, paid-up, irrevocable, worldwide license to publish or reproduce the published form of this work, or allow others to do so, for U.S. Government purposes. will approach that of Si devices in the next decade because cost reductions are accelerating [3]. The use of silicon carbide ( $\mathrm{SiC})$ provides advantages of high switching speeds, increased power density, high temperature operation, and reduced system losses. Even though SiC-device-based PV inverters are being designed and many technical challenges associated with them are being solved, a commercial-scale single-stage, two-level PV inverter operating at high dc-bus voltage with all grid-support functionalities has not yet been developed [4]. Furthermore, most SiC-based PV inverters demonstrated are developed using commercial power modules [4]-[6]. These power modules are not optimized to achieve the efficiency and power density target metrics defined by the U.S. Department of Energy Solar Energy Technologies Program [7]. The high switching speed realized by the $\mathrm{SiC}$ devices enables a reduction in the size of the ac-filter. Most SiC-based inverters developed use traditional inductors based on an E-I core or U-I core, which results in an asymmetrical flux distribution for the three phases [8], [9]. Furthermore, a PV inverter with advanced controller that enables grid-support functions as required by the IEEE 1547 standards for the interconnection of distributed energy resources (DERs), has not yet been developed and presented.

In this paper, a three-phase, $50-\mathrm{kW}, 480-\mathrm{V}$ SiC-based singlestage, two-level PV inverter is presented and validated. This paper elaborates on different parts of the inverter that have been optimized to exploit the advantages offered by $\mathrm{SiC}$ devices and then presents the results showing optimal performance of the developed inverter. Section II presents the development and evaluation of different parts of the inverter. This includes the development of the power modules and heatsink, the symmetrical Y-core filter inductors, the controller and the control algorithms, and the inverter thermal design. The validation of the developed inverter is presented in Section III through experimental results, quantifying the efficiency, output quality, and controller performance. The conclusions and main developments are summarized in Section IV.

\section{DEVELEOPED INVERTER}

In this section, the different parts of the developed PV inverter are discussed. The developed three-phase, 50-kW PV inverter uses SiC MOSFETS and diodes as the semiconductor devices in the power block, has new symmetrical Y-core inductors in the ac filter, and has a controller with advanced inverter functions for grid-support functionality. The electrical 


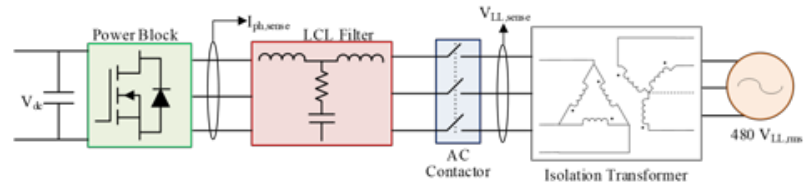

Fig. 1. Electrical schematic of the developed three-phase $50-\mathrm{kW}, 480 \mathrm{~V}$ inverter prototype setup.

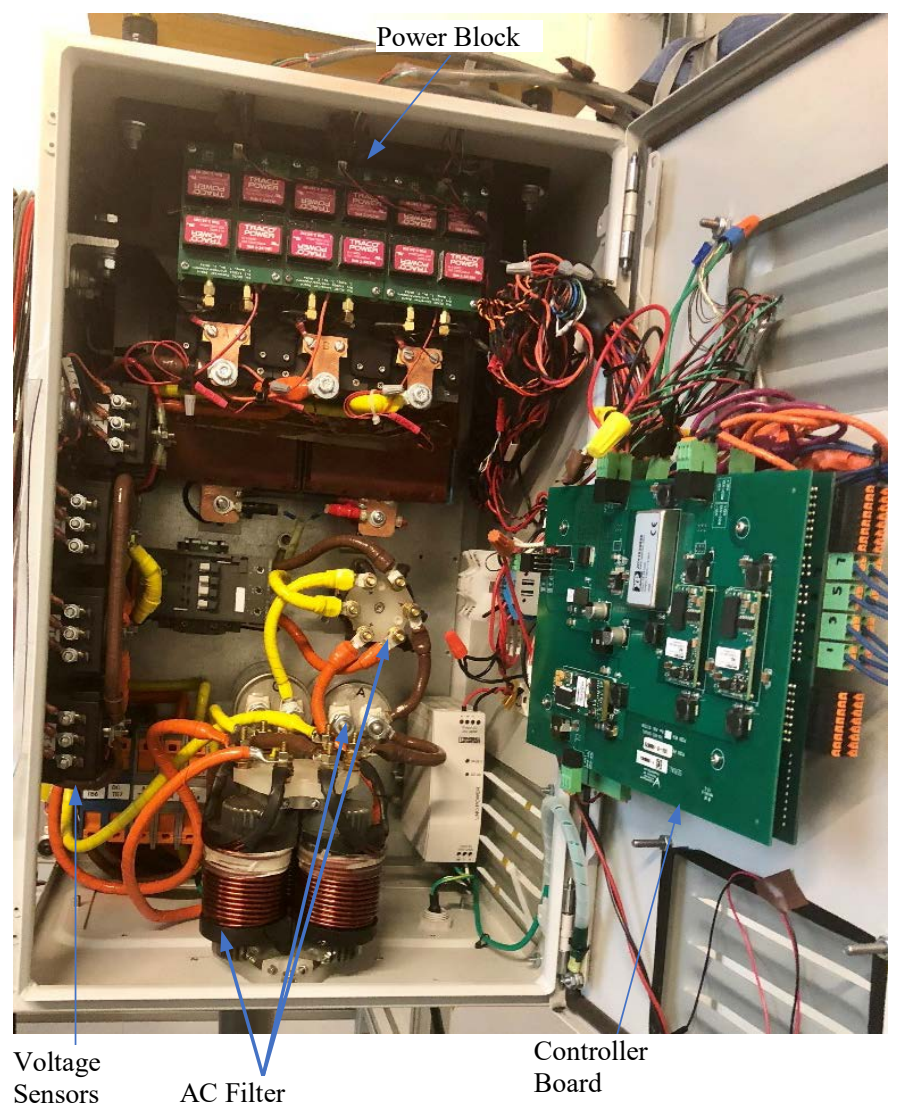

Fig. 2. Inside view of the developed three-phase, 50-kW, $480 \mathrm{~V}_{\mathrm{LL}, \mathrm{rms}} \mathrm{SiC}$ based inverter prototype.

schematic of the setup and the inside view of the developed inverter prototype are shown in Figs. 1 and 2, respectively. In the next subsection, the development and evaluation of the power modules is presented.

\section{A. 1.7-kV 50-kW PV Inverter Power Block}

Half-bridge power semiconductor modules are fabricated for the PV inverter using $1700 \mathrm{~V}$ bare die samples of $\mathrm{SiC}$ MOSFETs and SiC Schottky diodes. The current ratings of single SiC MOSFET and SiC Schottky diode bare die are around $34 \mathrm{~A}$ and $50 \mathrm{~A}$, respectively. Multiple devices are paralleled to achieve the required current rating. The main objective of the module design is to increase the overall heat dissipation area by splitting the phase leg module into two submodules - i.e., a high-side switch module and a low-side switch module - which are attached to two separate heatsinks. Each submodule consists of a direct bonded copper (DBC) substrate attached to the flow channel via thermal interface material. The aluminum flow channel is electrically insulated from the positive and negative dc-bus by the aluminum nitride

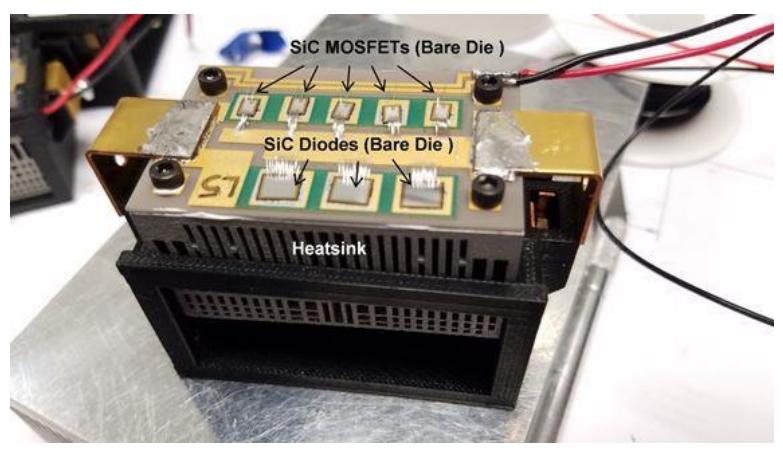

Fig. 3. Power module assembly.

substrate. The high-voltage dc-bus interconnects the power module from the left side of the airflow channel, and the gate driver and control interface on the right side. A decoupling circuit board, adjacent to the dc bus, is designed to minimize the power loop parasitic inductances and improve switching performance.

In addition, the heatsinks were optimized using genetic algorithm, a machine learning algorithm that imitates the natural evolution process proposed in the Darwinian evolutionary theory. While using genetic algorithms coded in MATLAB, to generate design chromosomes of heatsink, finite element analysis (FEA) simulations are used to evaluate the fitness value of each. Following the optimization method, a heatsink model was generated, and the detailed design and analysis of the heatsink has been previously presented in [10], [11].

The fabricated power module is shown in Fig. 3, where only the low-side switch of the phase leg module is shown. The highside switch has the same structure, which is reversely stacked on top of the low-side switch. The single-phase assembly with the fan is shown in Fig. 4. The volume of this single-phase power block is $\sim 20 \mathrm{in}^{3}$, and the total combined volume of the power stage for the three-phase inverter is $\sim 60 \mathrm{in}^{3}$. The development of the full power block and its evaluation are presented next.

The power block of the three-phase inverter mainly includes three air-cooled half-bridge power modules, fans, dc-link capacitors, dc bus bars, and gate drivers. The actual hardware prototype of the three-phase inverter is shown in Fig. 5, with an overall volume of $\sim 671 \mathrm{in}^{3}$. The power density for a $50-\mathrm{kW}$ operation is $75 \mathrm{~W} / \mathrm{in}^{3}$.

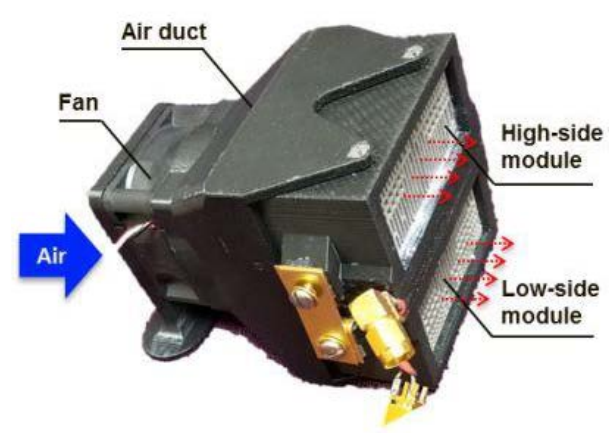

Fig. 4. Single-phase block assembly of the power stage. 


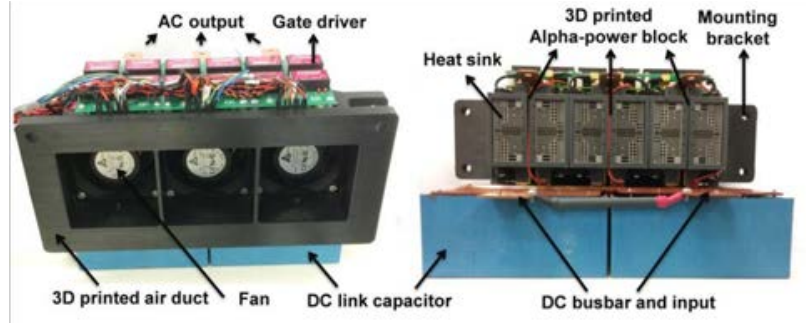

Fig. 5. Hardware prototype of 50-kW three phase power block: front view (left) and back view (right).

The developed power block was evaluated as an individual part before full system validation. Fig. 6 illustrates the threephase ac current when the three-phase power block operates at $1-\mathrm{kV}$ dc-bus voltage and approximately $48-\mathrm{kW}$ output power when supplying a stand-alone resistive load. The inverter ac output current is close to pure sinusoidal wave, with some switching ripples and minor distortion at the zero-crossing point. The switching ripple can be better suppressed with higher filtering inductance and/or higher order harmonic filters in the future grid tied operation. Based on the power analyzer measurement results, the inverter output ac current $\left(\mathrm{I}_{\mathrm{rms} 2}\right)$ is around $60 \mathrm{~A}$ rms with a total harmonic distortion (THD) of about $2.5 \%$. The inverter line-to-line fundamental RMS voltage is around $460 \mathrm{~V}\left(\mathrm{U}_{\mathrm{rms} 4}\right)$; however, the overall inverter line-toline rms voltage $\left(\mathrm{U}_{\mathrm{rms} 2}\right)$ is much higher than the fundamental value because of the high switching ripple and its side-band harmonics. The inverter input and output active power are $48.15 \mathrm{~kW}$ and $47.28 \mathrm{~kW}$, respectively, resulting in an efficiency of about $98.2 \%$.

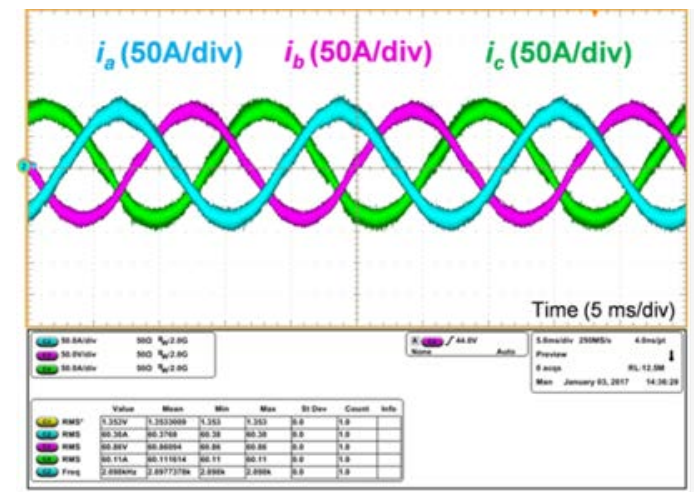

Fig. 6. Three-phase AC current of the three-phase power block operating at $1-\mathrm{kV}$ DC bus voltage and approximately $48-\mathrm{kW}$ output power.

The design, development, and evaluation of the inverterside and grid-side inductors of the LCL filter in the inverter is presented in the next subsection.

\section{B. AC Filter}

As shown in Fig. 1, an LCL filter is placed between the inverter and utility. Using [12]-[14], the desired values of the inverter-side inductance, capacitance, and line-side inductance were determined to be $188 \mu \mathrm{H}, 14 \mu \mathrm{F}$, and $35 \mu \mathrm{H}$, respectively.

A three-phase symmetrical Y-core inductor topology was used [15]. This arrangement is not subject to the inherent magnetic imbalance of three-phase E-core inductors. Further,

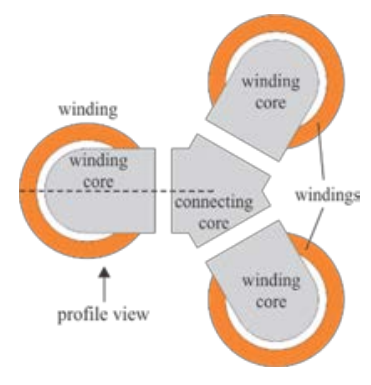

(a) Top view

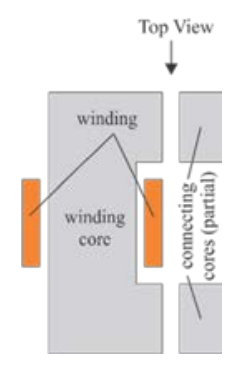

(b) Profile view
Fig. 7. Symmetrical Y-core inductor.

this coupled topology is smaller than using independent phase inductors. The Y-core inductor is compared to other topologies in [16]. Fig. 7 illustrates the magnetic arrangement of the Ycore inductor, with Fig. 7a (left) showing a top view, and Fig. $7 \mathrm{~b}$ (right) showing a profile view of one of three identical legs in a cross section (see dashed line of Fig. 7a). The windings are wound around winding cores; the flux is combined centrally through top and bottom connecting cores. Air gaps are placed between the winding and connecting cores. In this effort, a laminated magnetic steel core with high Si content is used. A photograph of the two Y-core inductors is given in Fig 8. The first step in the inductor design was to execute a time-domain simulation of the sysytem based on the highest input voltage and full-load conditions. This simulation is used to establish the current spectrum seen in the three phases.

The inductor design was performed using a poly-physics multi-objective optimization in which encapsulating volume and loss are minimized subject to constraints. Constraints include bending radius, packing factor, aspect ratio, mass, current density, inductance, inductance symmetry, peak winding temperature, peak bobbin temperature, and loss. The particular design was chosen from the resulting Pareto-optimal front. A paper fully describing the inductor design process is forthcoming.

The $q$ - and $d$-axis inductances were tested using the procedure described in [16]. Figs. 9 and 10 depict the absolute inductance (flux linkage divided by current) versus current for the two inductors. Therein, the 'target' inductance describes the desired value, and 'DM' denotes prediction by the Design Model [16]. The legends ' $\mathrm{DM}^{*} 0.9$ ' and ' $\mathrm{DM} * 1.1$ ' indicate a deviation of $\pm 10 \%$ from the design model. There is an excellent agreement between the DM and measured inductance for the inverter-side inductor. In the case of the line-side inductor, the measured inductance is greater than predicted. A possible explanation is that in the physically smaller line-side

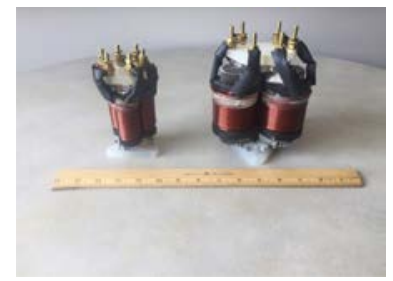

Fig. 8. Line side (right) and inverter side (left) inductors. 


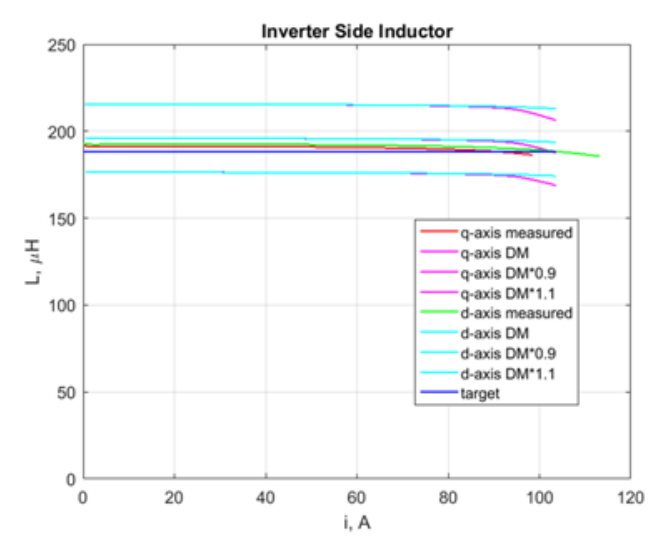

Fig. 9. Inverter-side inductance.

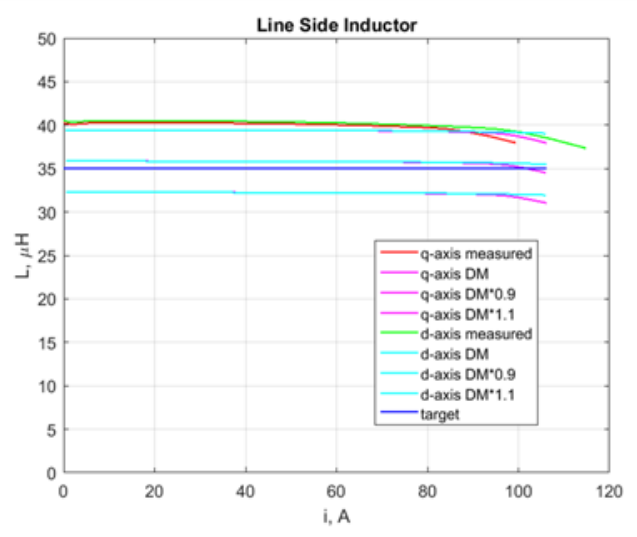

Fig. 10. Line-side inductance.

inductor, variances in air gap and leakage paths have a relatively larger impact than in the larger inductor.

\section{Controller and Control Algorithm}

National Instrument's single-board RIO (SBRIO) with General Purpose Inverter Controller (GPIC) mezzanine card were selected as the primary controller for the inverter prototype. The SBRIO is composed of a Xilinx Zynq-7000, 667 $\mathrm{MHz}$ dual-core ARM Cortex-A9 processor, an Artix-7 field programmable gate array (FPGA), and a mezzanine card connector that is used to connect with GPIC. Furthermore, interface boards were developed to tap the FPGA output directly, in order to implement high switching frequencies enabled by the $\mathrm{SiC}$ devices. Based on the transient-domain inverter model and the current-control, advanced inverter control functions including volt-VAr (VVAR), volt-watt (VWATT), and frequency-watt (FWATT) are developed and implemented. The developed control algorithms were validated using a controller hardware-in-the-loop testbed, developed in this project that can be used to trouble-shoot and validate control algorithms without the risk of damaging the hardware [17]. The complete controller assembly is shown in Fig. 11. The developed control algorithms are evaluated, and the validation results are presented in Section III.

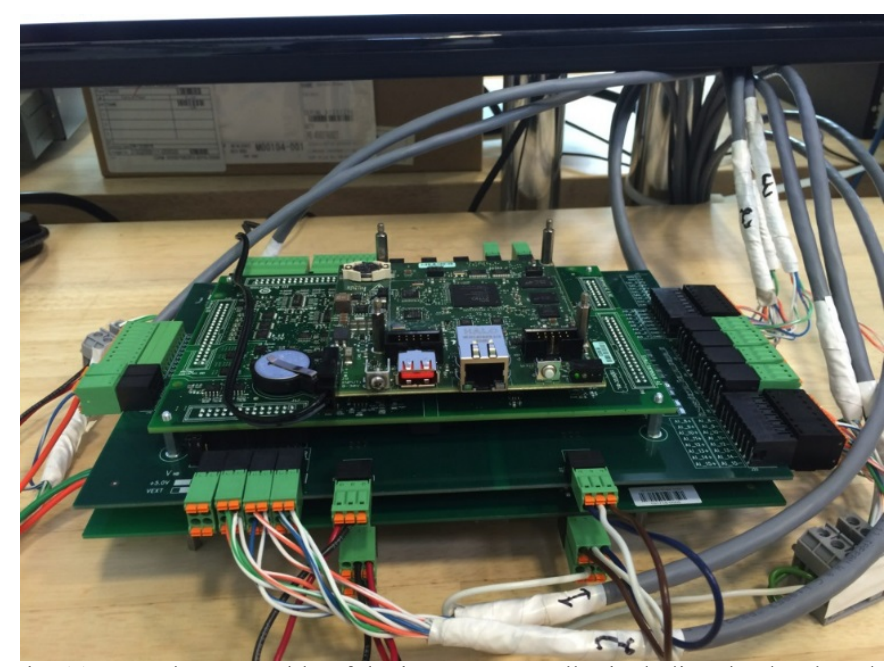

Fig. 11. Complete assembly of the inverter controller including the developed interface boards.

\section{Inverter Assembly and Thermal Design}

Components in the inverter system feature different thermal specifications, and the entire system is also defined with environmental and mechanical specifications. Therefore, the system thermal design is key to the packaging and thermal management of the inverter system. The goal is to satisfy the component thermal limitations while pushing the volumetric power density. The layout of the major components inside the inverter is shown in Fig. 12. The only cooling method for thermal management is air cooling, and the incoming air temperature is chosen to be $40^{\circ} \mathrm{C}$.

During the design of the power block, three fans were used to remove the excessive heat from the inverter. The fans were attached to the power modules through a specially-designed air duct to maximize the air volume passing through the power modules. With a large air outlet on the top side of the enclosure, the fans pull the hot air through the heatsinks, which is then expelled into the ambient environment. The reason why the power block is installed close to the air exit is because among all the components, the power block generates the largest amount of heat, and being close to the end of the air cooling

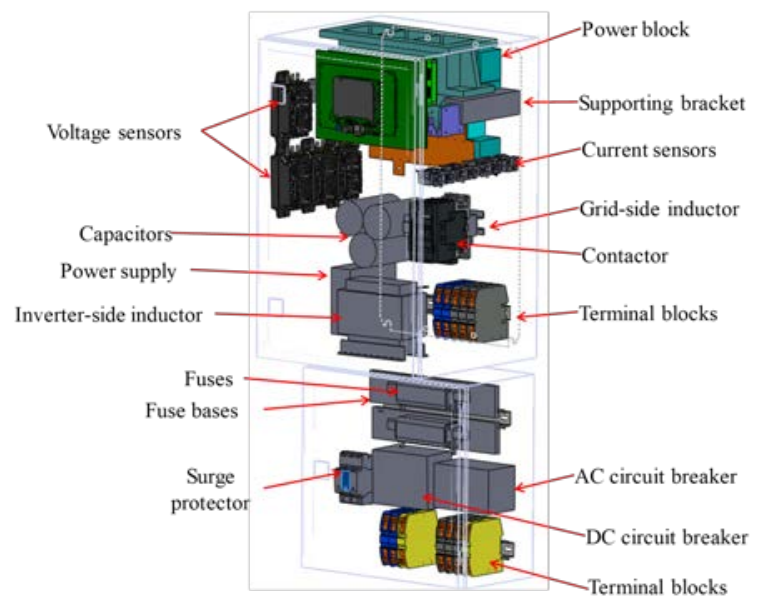

Fig. 12. Layout of components in the inverter system. 


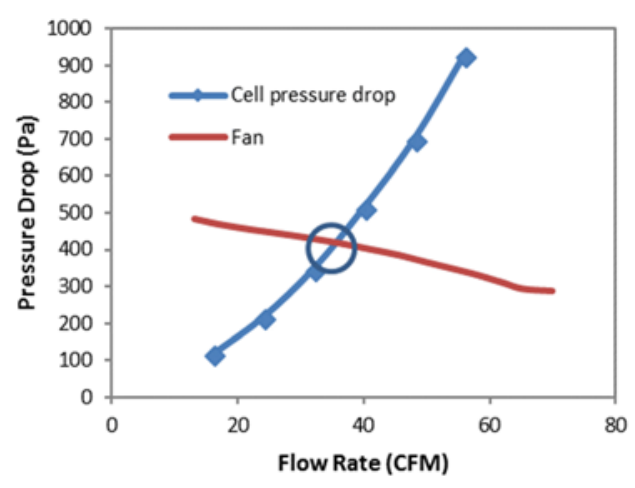

Fig. 13. Comparison of heat sink pressure drop and fan performance curve. It is for one power module.

path avoids heating other components and mitigates the need for additional cooling.

The cooling air enters the enclosure through several vents on the enclosure. The determination of the effective cooling air inlets and passages to dissipate thermal energy from these components is another important issue associated with the thermal design. The determination of the size and position of the air vents helps fulfill the temperature restrictions and thermal targets for the components. A preliminary simulation shows that to limit the power block's temperature rise to less than $40^{\circ} \mathrm{C}$, more than $100 \mathrm{in}^{2}$ of venting area is required for the ambient air to enter the enclosure. Another factor associated with the cooling performance is the volumetric flow rate of the fan. To determine the flow rate, heat sink pressure drop and fan performance must be known. In this analysis, the measured pressure drop versus flow rate for the fan was graphed with the heat exchanger pressure drop to retrieve the flow rate, as shown in Fig. 14. The working volumetric flow rate is determined to be 36 cubic feet per minute (CFM) for a single phase-leg and fan ( $1 / 3$ of power block).

Based on the inverter component layout, thermal specifications, and the airflow rate, thermal analyses were conducted to obtain the system-level temperature distribution inside the inverter. Two types of thermal analyses were applied

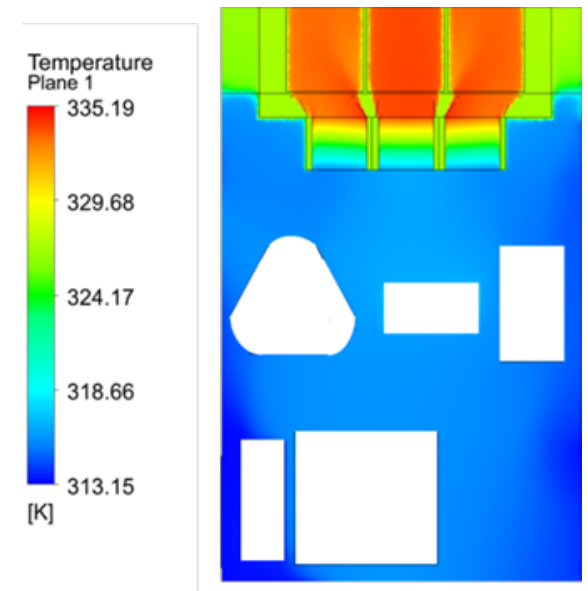

Fig. 14. Interior temperature distribution of the inverter. to the system. The first is a qualitative estimation based on the conservation of energy and constant mass flow rate. This method assumes that all the generated thermal energy is dissipated into the cooling air and there is no heat loss via other media. Meanwhile, the mass flow rate through each power module is equal and constant. It provides us an approximated temperature profile inside the inverter. Another more comprehensive method of thermal analysis is computational fluid dynamics (CFD) simulation. One advantage of CFD simulation is that it presents the details of the airflow, temperature field, and pressure drop. Even though the two thermal analysis methods seem obviously distinct, they provided very close results under appropriate assumptions and can validate each other.

The first method used the flow rate of 36 CFM to estimate the increase of air temperature after passing through the power block, and it was calculated to be $15^{\circ} \mathrm{C}$. The second method simulated the entire inverter system; the updated temperature distribution within the inverter cabinet is presented in Fig. 14. This graph shows the relative impact of the inductor heat and power block heat based on the air temperature. Because of the high volumetric flow of air, the inductors cause a relatively small increase in the air temperature before the air enters the power block. The power block still generates the most heat and highest temperature rise. Dedicated fans are required to effectively conduct the hot air away from the power block. The temperature rise of the cooling air after passing through the power block is $17^{\circ} \mathrm{C}$. The higher temperature results from the slightly reduced airflow caused by the higher system pressure drop. Here, the simulation is system-level, and simplifications are made when developing the power block and inductor models.

The validation of the inverter and control algorithms along with quantification of the inverter output quality and efficiency is presented in the next section.

\section{PROTOTYPE INVERTER VALIDATION}

In this section, first the inverter operation in voltage control mode and current mode is presented. The quality of the inverter output waveforms is quantified along with efficiency. Furthermore, the inverter operation during various grid events is presented to demonstrate the grid-support functions. The electrical schematic of the experimental setup for all the gridconnected tests is shown in Fig. 1. The output from the inverter is connected to the grid through a $\Delta$-Y transformer. This transformer is used to limit the common-mode current, because a common-mode choke was not included in the experimental setup. The grid was formed using Ametek's RS90 grid simulator. The inverter switching frequency for these tests is 20 $\mathrm{kHz}$, and the dc-bus voltage is maintained at about $900 \mathrm{~V}$.

The inverter output waveforms when operating in openloop, voltage-control mode connected to a resistive load is shown in Fig. 15. The THD of the load currents for $40 \mathrm{~kW}$ and $50 \mathrm{~kW}$ power being supplied by the inverter is measured to be about $2.35 \%$ and $2.14 \%$, respectively. Similarly, inverter output waveforms when operating in closed-loop, current-control mode connected to a grid simulator are shown in Fig. 16. The THD of the current injected into the grid is measured to be 


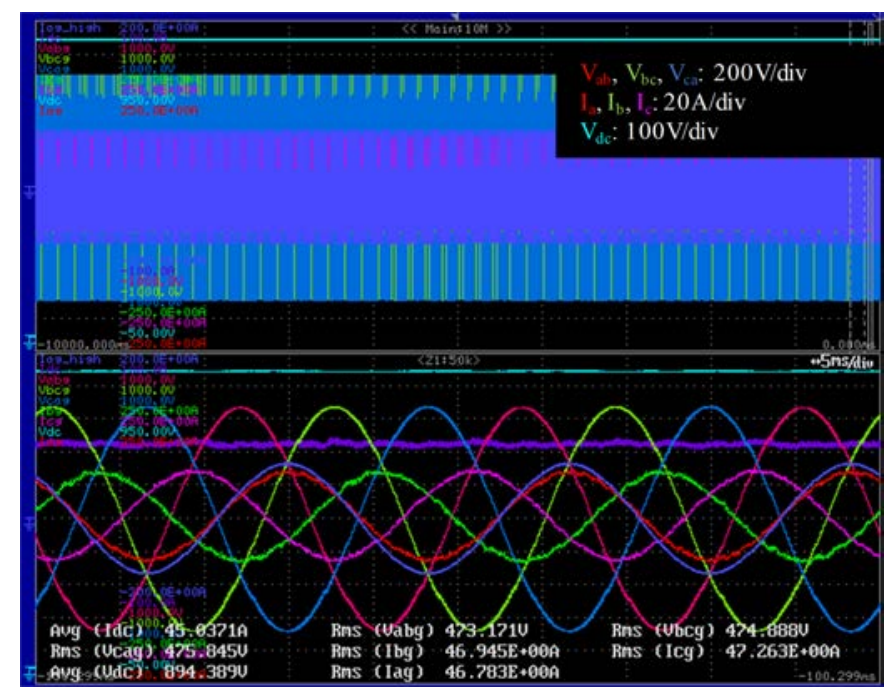

(a) Output Power $=40 \mathrm{~kW}$

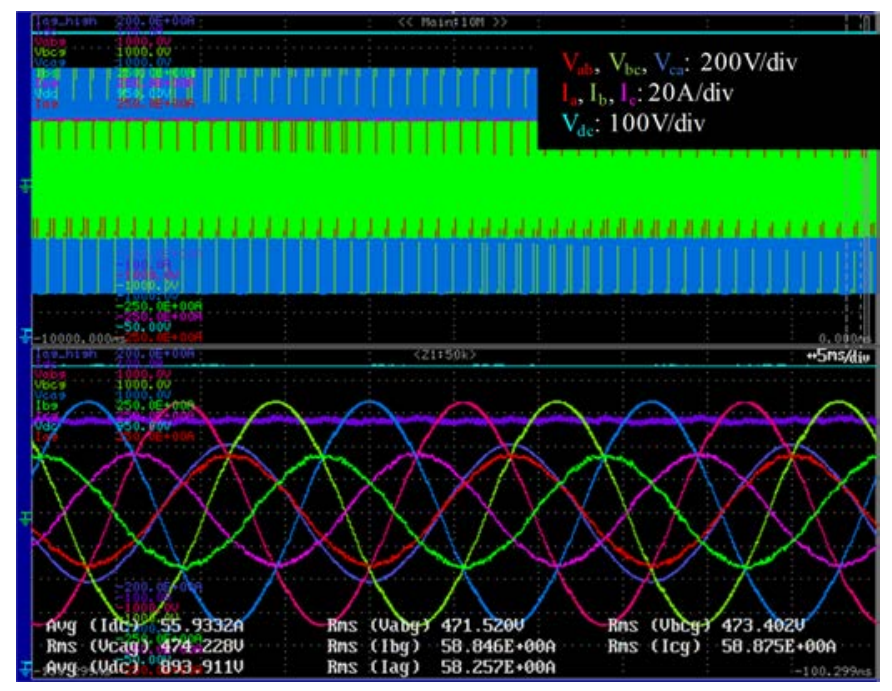

(b) Output Power $=50 \mathrm{~kW}$

Fig. 15. Measured three-phase waveforms of line-to-line voltages and line currents for different output power and output line-to-line voltage of $480 \mathrm{~V}$ for open-loop voltage-control mode of operation. AC-voltage scale: $200 \mathrm{~V} /$ div, DC-voltage scale: 100V/div, I scale: $20 \mathrm{~A} / \mathrm{div}$.

$3.62 \%$ and $3.94 \%$. The inverter efficiency as measured at different loads with the dc-bus voltage of $900 \mathrm{~V}$ is shown in Fig. 17. The peak efficiency of the inverter is computed to be $98.2 \pm 0.053 \%$ whereas the California Energy Commission efficiency is computed to be about $97.72 \pm 0.05 \%$. It should be noted that the efficiency calculation includes losses in the controller and the thermal management system (fans). The measured efficiency is higher than conventional Si-based PV inverters.

The next set of tests were done to verify the developed advanced inverter controls and to validate inverter performance during different grid events. The VVAR controls allows the inverter to help maintain the grid voltage by injecting or absorbing reactive power during any voltage event. Fig 18 shows the VVAR curve used for the verification. The grid simulator used for the tests was coded to provide voltage steps at different time intervals, as shown in Fig. 19. The inverter was capable of changing the reactive power injected into the grid

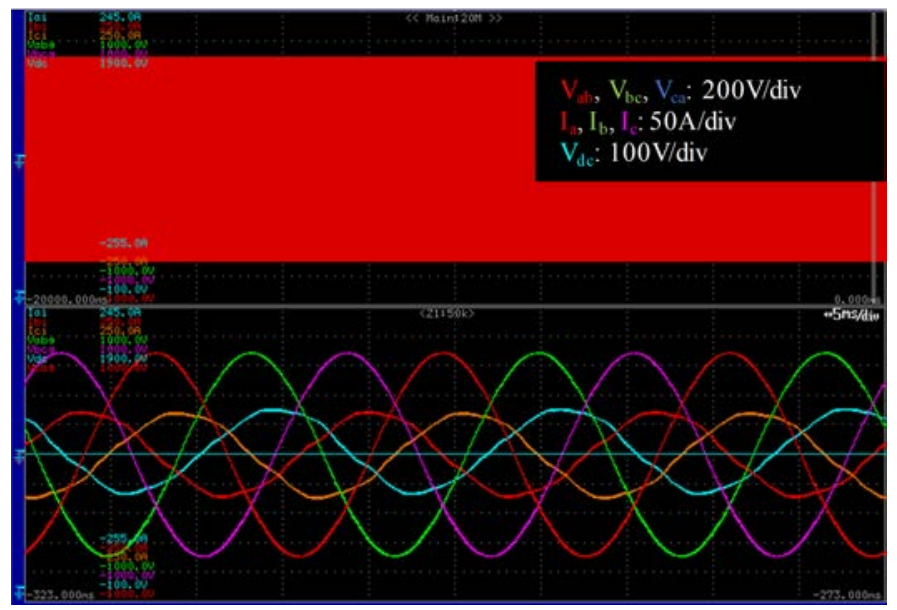

(a) Output power $=41.5 \mathrm{~kW}$

Fig. 16. Measured three-phase waveforms of line-to-line voltages and line currents for different output power in current-control mode of operation at $897 \mathrm{~V}$ dc bus.(a) ac-voltage scale: $200 \mathrm{~V} /$ div, dc-voltage scale: 100V/div, I scale: $50 \mathrm{~A} /$ div; (b) ac-voltage scale: $200 \mathrm{~V} /$ div, dc-voltage scale: $100 \mathrm{~V} / \mathrm{div}$, I scale: $20 \mathrm{~A} / \mathrm{div}$. through these voltage changes. It should be noted that the voltage results in Fig. 19 is the peak voltage measured at the point of common coupling (PCC).

The next verification is for VWATT grid-support function verification. The VWATT curve used for the verification is presented in Fig. 20. During this test, the grid simulator was programmed to provide voltage steps, as shown in Fig. 21. The reference active power is calculated based on the programmed VWATT curve (see Figs. 20 and 21). It can be observed from Fig. 21 that the active power injected into the grid followed the reference computed from the VWATT curve.

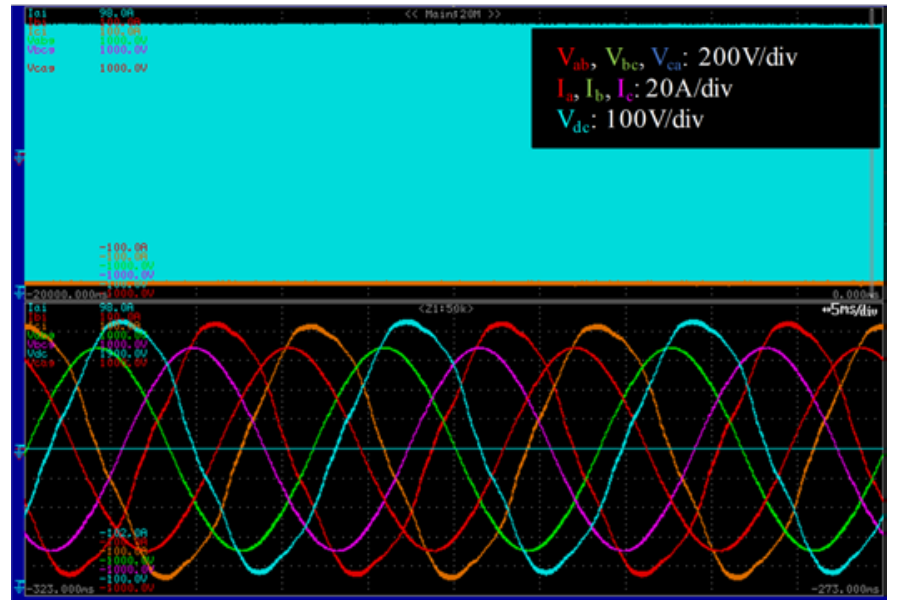

(b) Output power $=50 \mathrm{~kW}$ 


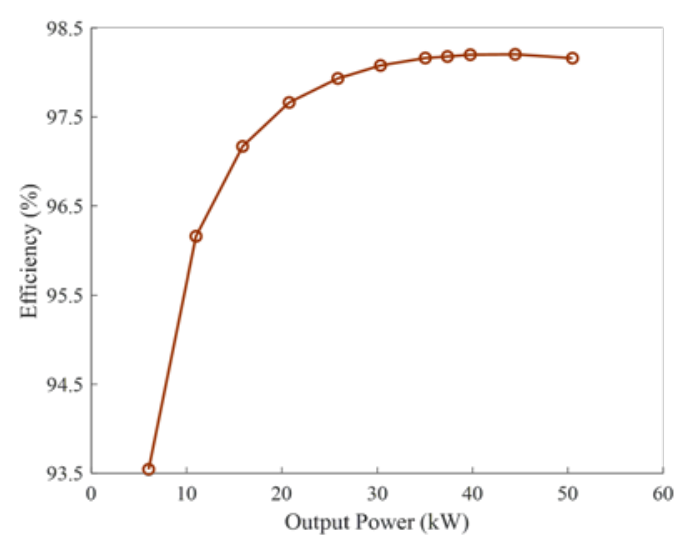

Fig. 17. Measured inverter efficiency at different loads.

In addition to regulation functions, voltage and frequency ride-through are implemented in the controller. Fig. 22 provides the experimental result from a sample voltage ride-through testing. In this verification, the overvoltage 1 (OVR1) setting was tested. This OVR1 setting gets activated when the grid voltage is more than $110 \%$ but less than $120 \%$ of the nominal voltage. For that operating region, the inverter is required to ride-through until 0.92 seconds [18]. If the voltage does not return to the normal range by that time, the inverter should trip. The test results show that the voltage exceeded 1.1 p.u. (431

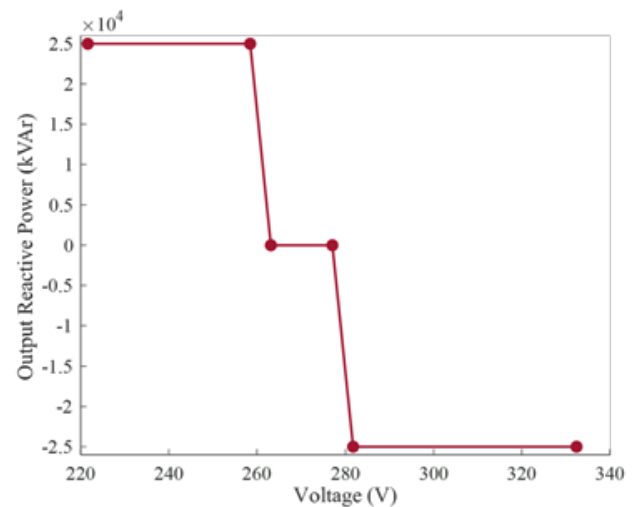

Fig. 18. Volt-VAr curve used in experimental verification.

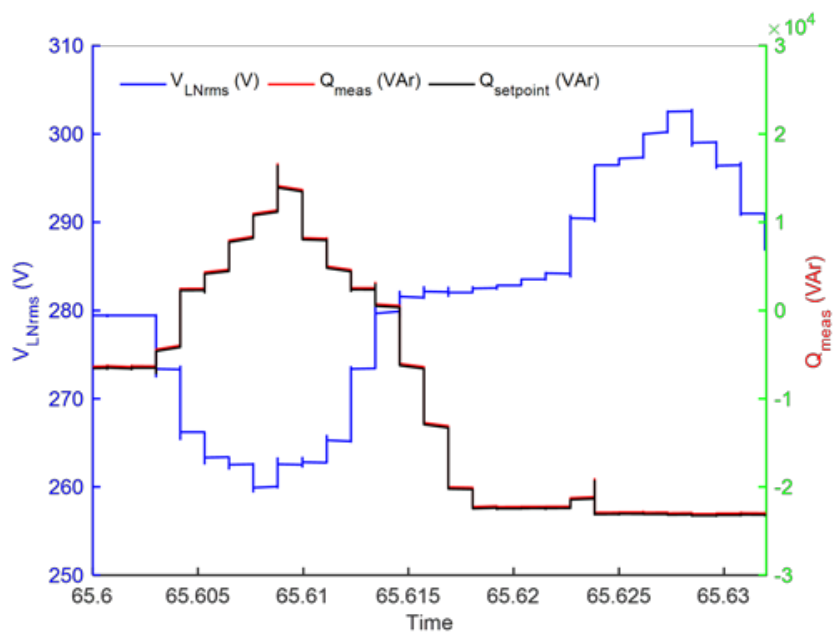

Fig. 19. Test results showing voltage steps, reference, and measured reactive power injected into the grid.

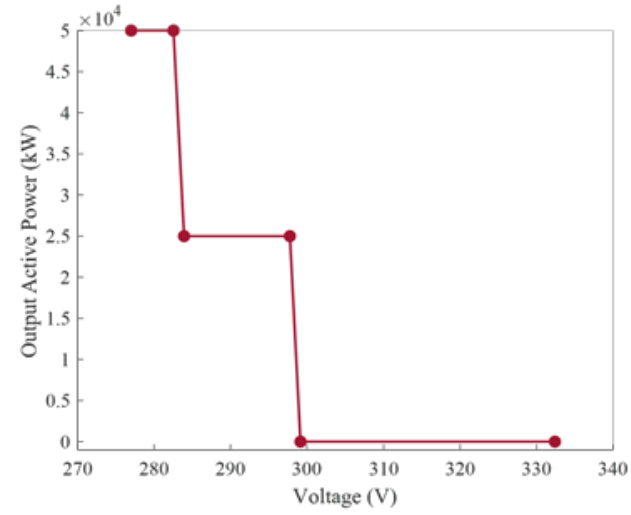

Fig. 20. Volt-Watt curve used in experimental verification.

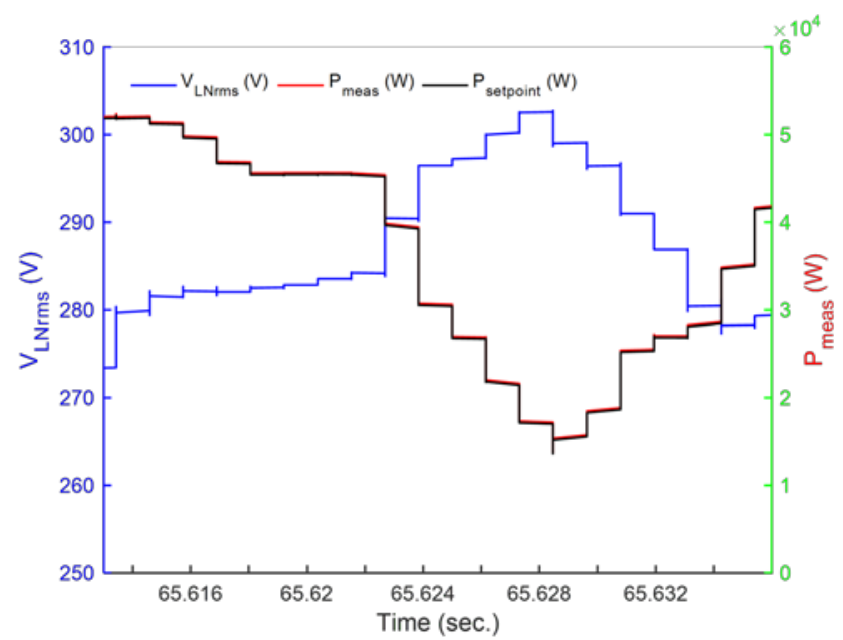

Fig. 21. Test results showing voltage steps, reference, and measured active power injected into the grid.

$\left.\mathrm{V}_{\text {ph,peak }}\right)$ at about 0.45 seconds. At 0.75 seconds, the voltage reduced to normal range, and thus it did not trigger the trip signal. At 1.3 seconds, the voltage increased to 1.1 p.u. and stayed at this voltage level. The trip signal was triggered after 0.92 second, as expected and required. It should be noted that,

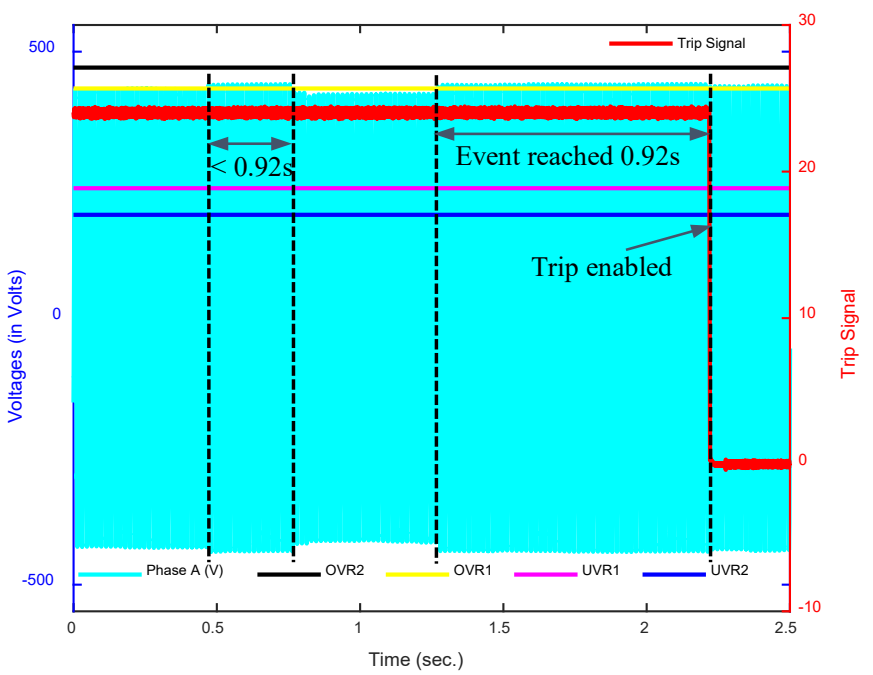

Fig. 22. Experimental results for voltage ride-through showing two overvoltage events. 
the trip signal shown in Fig. 22 is the actual $24 \mathrm{~V}$ signal being sent to the three-phase AC contactor by the controller. The second OVR1 event occurs at about 1.3 seconds, and when the ride-though limit is reached at about 2.22 seconds, the controller sends $0 \mathrm{~V}$ to the contactor coil to trip it.

\section{CONCLUSION}

In this paper a three-phase, two-level, $480 \mathrm{~V}, 50-\mathrm{kW}$ PV inverter designed with $\mathrm{SiC}$ power devices has been presented and validated. The different parts of the inverter have been presented to demonstrate the optimization in each to achieve full advantage of the high-voltage, high switching speed of the $\mathrm{SiC}$ devices. The inverter functionality has been tested and its performance has been quantified in terms of output waveform THDs and inverter efficiency at different loads and in both voltage and current-control modes of operation. The acceptable inverter performance has also been demonstrated while the inverter is performing grid-support functions. The development of such an inverter and its validation will encourage PV inverter manufacturers to adopt wide-bandgap devices in their products, resulting in higher efficiency and low-cost inverters. This will further facilitate the proliferation of PV into the electric power systems.

\section{ACKNOWLEDGMENT}

The authors gratefully acknowledge the support of Guohui Yuan and Jeremiah Miller of the U.S. Department of Energy Solar Energy technologies Program, Systems Integration Subprogram, for their valuable advice and funding for this work.

\section{REFERENCES}

[1] Department of Energy, "Power America", https://energy.gov/eere/amo/power-america, Last accessed October 09, 2017.

[2] A. Hefner et al., "Recent Advances in High-Voltage, High-Frequency Silicon-Carbide Power Devices," Conference Record of the 2006 IEEE Industry Applications Conference Forty-First IAS Annual Meeting, Tampa, FL, 2006, pp. 330-337.

[3] N. Iwamuro and T. Laska, "IGBT History, State-of-the-Art, and Future Prospects," in IEEE Transactions on Electron Devices, vol. 64, no. 3, pp. 741-752, March 2017.

[4] Y. Shi, L. Wang, R. Xie, Y. Shi and H. Li, "A 60-kW 3-kW/kg Five-Level T-Type SiC PV Inverter With 99.2\% Peak Efficiency," in IEEE Transactions on Industrial Electronics, vol. 64, no. 11, pp. 9144-9154, Nov. 2017.
[5] L. C. Breazeale and R. Ayyanar, "A photovoltaic array transformer-less inverter with film capacitors and silicon carbide transistors," IEEE Trans. Power Electron., vol. 30, no. 3, pp. 1297-1305, Mar. 2015.

[6] A. Hatanaka, H. Kageyama, and T. Masuda, "A 160-kW high-efficiency photovoltaic inverter with paralleled SiC-MOSFET modules for largescale solar power," in Proc. IEEE International Telecommunications Energy Conference (INTELEC), 2015, pp. 1-5.

[7] Guohui Yuan, Developing Next Generation Power Electronics to Enable 100 s GW of Solar, DOE SunShot presentation, available online at: https://www.energy.gov/sites/prod/files/2016/11/f34/keynote_SunShot_ Yuan.pdf, Last accessed June 15, 2018.

[8] K. Fujii, Y. Noto, M. Oshima and Y. Okuma, "1-MW solar power inverter with boost converter using all $\mathrm{SiC}$ power module," 2015 17th European Conference on Power Electronics and Applications (EPE'15 ECCEEurope), Geneva, 2015, pp. 1-10.

[9] G. Rizzoli, M. Mengoni, L. Zarri, A. Tani, G. Serra and D. Casadei, "Comparative Experimental Evaluation of Zero-Voltage Switching Si Inverters and Hard-Switching Si and SiC Inverters," in IEEE Journal of Emerging and Selected Topics in Power Electronics (Early Access).

[10] M. Chinthavali, Z. Wang, S. Campbell, T. Wu, and B. Ozpineci, "50-kW $1 \mathrm{kV}$ DC bus air-cooled inverter with $1.7 \mathrm{kV} \mathrm{SiC} \mathrm{MOSFETs} \mathrm{and} \mathrm{3D-}$ printed novel power module packaging structure for grid applications", 2018 IEEE Applied Power Electronics Conference and Exposition (APEC), 2018, pp. 133-140.

[11] T. Wu, B. Ozpineci, M. Chinthavali, Z. Wang, S. Debnath, and S. Campbell, "Design and optimization of 3D printed air-cooled heatsinks based on genetic algorithms", 2017 IEEE Transportation Electrification Conference and Expo (ITEC)., Jun. 2017, pp. 650-655.

[12] R. N. Beres, X. Wang, M. Liserre, F. Blaabjerg and C. L. Bak, "A Review of Passive Power Filters for Three-Phase Grid-Connected Voltage-Source Converters," in IEEE Journal of Emerging and Selected Topics in Power Electronics, vol. 4, no. 1, pp. 54-69, March 2016.

[13] M. Liserre, F. Blaabjerg and S. Hansen, "Design and control of an LCLfilter-based three-phase active rectifier," in IEEE Transactions on Industry Applications, vol. 41, no. 5, pp. 1281-1291, Sept.-Oct. 2005.

[14] Marco Liserre, Frede Blaabjerg \& Antonio Dell'Aquila (2004) Step-bystep design procedure for a grid-connected three-phase PWM voltage source converter, International Journal of Electronics, 91:8, 445-460.

[15] S. D. Sudhoff, R. R. Swanson, A. E. Kasha and V. S. Duppalli, "Magnetic Analysis of Symmetrical 3-Phase Y-Core Inductors," in IEEE Transactions on Energy Conversion, vol. PP, no. 99, pp. 1-1.

[16] V. S. Duppalli and S. Sudhoff, "Power density comparison of three-phase AC inductor architectures," 2017 IEEE Electric Ship Technologies Symposium (ESTS), Arlington, VA, 2017, pp. 217-224.

[17] K. Prabakar, M. Shirazi, A. Singh and S. Chakraborty, "Advanced photovoltaic inverter control development and validation in a controllerhardware-in-the-loop test bed," 2017 IEEE Energy Conversion Congress and Exposition (ECCE), Cincinnati, OH, 2017, pp. 1673-1679.

[18] Hawaiian Electric Rule No. 14, Paragraph H: Interconnection of Distributed Generating Facilities with the Company's Distribution System (Rule 14H), The Hawaiian Electric Companies. 